\title{
Filosofia da Educação: multiculturalismo e interculturalismo
}

Philosophy of Education: multiculturalism and interculturality Paolo Nosella

Resumo: O texto, primeiramente, define e distingue os conceitos de multiculturalismo e de interculturalidade. Em seguida, relata situações de destruição das culturas e territórios "capixabas" (do estado do Espírito Santo/Brasil) pela ação de empresas multinacionais. Finalmente, ilustra a iniciativa educacional da Pedagogia da Alternância, didaticamente assentada na valorização das culturas locais. Nessas escolas ensina-se que é possível uma dialética diferente entre a cultura local e o saber globalizado. Tais escolas, atualmente, existem em 21 Estados da Federação.

Palavras-chave: Territorialidade; multiculturalismo; culturas locais; educação; Pedagogia da Alternância.

Abstract: The text, first, defines and distinguishes the concepts of multiculturalism and interculturality. Then, it reports situations of the destruction of the culture and territories of the "capixabas" (people from the state of Espirito Santo in Brasil) by the action of multinational corporations. Finally, it illustrates the educational initiative of Alternance Pedagogy, didactically grounded in appreciation of local cultures. In these schools it is taught that it is possible a different dialectic between the local culture and globalized knowledge. Such schools currently exist in 21 states of the states of the Brasilian Federation.

Key words: Territoriality; multiculturalism; local cultures; education; Alternance Pedagogy.

\section{Questão semântica}

Sabemos que o interculturalismo não é um fenômeno específico da atualidade, pois é um fenômeno primordial na história da humanidade. Hoje, entretanto, utiliza-se mais frequentemente a expressão multiculturalismo. Os dois termos são equivalentes? São sinônimos? Qual dos dois é mais apropriado ao debate atual?

À primeira vista, parece não haver diferença significativa entre os dois. Os prefixos "inter" e "multi", entretanto, conotam diferenças significativas: inter refere-se a intercâmbio, integração, síntese, ecletismo, unificação cultural; multi refere-se a várias culturas justapostas ou até contrapostas, refratárias a um unitário processo de integração e de hegemonia político-cultural, permanecendo, portanto, em tensão entre si. Nesse sentido, enquanto o interculturalismo já 
conota solução de conflito, o multiculturalismo expressa contraposição entre culturas diferentes e, portanto, exige do poder do Estado políticas públicas apropriadas a esses conflitos.

O conceito e termo "multiculturalismo" é hoje mais utilizado, carrega maior densidade política, diz respeito diretamente à temática das políticas públicas necessárias aos governos diante da "coexistência de várias culturas num mesmo território". O Dicionário Italiano Garzanti é explícito: "Política orientada à tutela da identidade cultural dos grupos étnicos que compõem um estado." (GARZANTI, 2011, p. 1584, tradução do autor). Observa-se que no mesmo dicionário, no verbete interculturale, se lê: "comum a mais culturas, que se verifica entre mais culturas" (p. 1275, tradução do autor). No Dicionário Houaiss da Língua Portuguesa (HOUAISS, 2001, p. 1976), no verbete multiculturalismo, se lê: "Coexistência de várias culturas num mesmo território, país etc.".

Em síntese: os dois termos convergem numa mesma problemática geral, todavia, a ênfase semântica é diferenciada e o debate teórico atual confere ao termo "multiculturalismo" um sentido diretamente político, normativo e ideológico, menos pronunciado na expressão interculturalidade. Com precisão conceitual, Maroussia Raveaud sintetiza:

A maior parte da sociedade - do ponto de vista cultural - não é
homogênea, é 'multicultural' no sentido descritivo do termo. Foi,
no entanto, no sentido normativo e ideológico que o termo
multicultural tem sido profusamente utilizado, desde a década de
1970, para designar um programa político que se apoia no
reconhecimento e na valorização de filiações particulares,
inscrevendo-as no espaço público. (RAVEAUD, 2011, p. 592)

No mesmo sentido, o jornalista e politólogo Antonio Gambino, analisando a origem e problemática relativas ao multiculturalismo, escreve:

O termo 'multiculturalismo' tem adquirido, há pelo menos dez anos, uma posição central no debate político e sociológico do mundo ocidental. Mas, o que precisamente significa quando o utilizamos? Não, obviamente, o mero fato de que em nosso planeta estiveram sempre presentes culturas e civilizações diferentes entre si e que desse pluralismo de formas de pensar e de viver os homens sempre tiveram consciência, mas o que se quer sublinear, quando se fala de multiculturalismo, é uma exigência, ou seja, a necessidade de que se estabeleça entre orientações e atitudes diferentes, e às vezes opostas, uma 
relação de coexistência e recíproca aceitação. (GAMBINO, 2001, p. 17) (tradução do autor)

Todavia, se a expressão "multiculturalismo" é hoje mais utilizada e carrega maior densidade política, a expressão "interculturalidade", utilizada por vários estudiosos, carrega semanticamente forte densidade ética por apontar uma direção valorativa à tensão multiculturalista. Com efeito, é esse o sentido assinalado no artigo de Stefania Tarim, Etica e politica nell'epoca dell'interculturalitá, no qual pergunta: "é hoje possível renunciar a projetar e construir um sistema de valores no qual todas as culturas possam se encontrar?" (TARIM, 2010, p. 63-66, tradução do autor). Tarim, arrolando um conjunto de autores e obras, defende a proposta do "universalismo crítico" e dismo que, de forma geral, ocorre em todas as sociedades ocidentais, não é homogêneo, ao contrário, conhece numerosas variantes. Uma delas, por exemplo, é a complexa e ardorosa movimentação política existente hoje no Brasil, onde, sobretudo a partir da década de setenta, existe um "Movimento de Educação do Campo" em ascensão, pelo qual, além das igrejas, muitas organizações da sociedade civil reivindicam e articulam específicas políticas públicas multiculturais, cujo ideário é o desenvolvimento sustentável por meio de uma educação voltada para os valores da territorialidade. Tal movimento comprova que o conflito entre as diferentes culturas, a do campo e a urbana, não está resolvido, ao contrário, demarca territórios contrapostos. Infelizmente, esta categoria, território, foi teoricamente negligenciada pelos estudiosos do fenômeno multicultural e, consequentemente, pelas instituições escolares. Com este texto, pretendo reduzir essa lacuna.

\section{O território e o capital financeiro: recordações pessoais}

A íntima correlação entre território e cultura está registrada na própria linguagem que nos adverte ser o homem relacionamento radical e universal com sua terra, com seu território de origem. O homem se define como habitante e filho da terra. Tal correlação inscrita na linguagem é assim comentada por Saviani: 
a própria etimologia da palavra latina "homo", da qual, pelo acusativo "hominem", derivou o vocábulo português homem, originariamente significa o nascido da terra, o terrestre, o habitante da terra. (SAVIANI, Prefácio, in NOSELLA, 2012a).

Ou seja, território não é um espaço abstrato do planeta, é uma relação cultural que denota concepção de vida e de valores; expressa identificação econômica, social e cultural do ser humano, conforme definição tão cara a Milton Santos: "A territorialidade humana pressupõe também a preocupação com o destino, construção do futuro, o que, entre os seres vivos, é privilégio do homem." (SANTOS, 2011, p. 19).

O território confere concretude à própria história humana, entretanto, o instrumento técnico, informacional e financeiro lhe confere a dimensão abstrata globalizante. Ou seja, com meios técnicos e com dinheiro o homem conquista, invade, domina os territórios, estabelecendo neles, em dimensões globais, o conflito entre culturas e até no interior da mesma. Com efeito, "a divisão territorial do trabalho, cria uma nova hierarquia entre lugares, redefinindo, a cada momento, a capacidade de agir das pessoas, das firmas e das instituições" (SANTOS, 2011, p. 21).

O homem do campo compreendera, há tempo, que existe uma violenta contraposição entre território e capital global. Pequenos agricultores familiares, imigrantes, comunidades indígenas, quilombolas e pomeranas, entre outras, buscaram e buscam novos caminhos que preservem suas características culturais sem isolacionismo nem fobia da modernidade técnico-científica. Por isso, concluem que a escola, visando à interculturalidade da sociedade, precisa integrar em seu percurso formativo o enraizamento cultural no território pela aprendizagem da ciência universal e pelo uso de novos e modernos instrumentos de produção.

Permitam-me falar, para dar um exemplo, de um território (o Estado do Espírito Santo), onde desembarquei, em 1967, de um navio cargueiro que ancorou no porto de Tubarão de Vitória-ES. São recordações pessoais que ilustram a perversa contraposição entre culturas territoriais e políticas "nacionais" convenientes ao capital global. 
Presenciei, nos anos de 1968/69, às sondagens socioambientais realizadas no litoral de Guaraparí e Anchieta (E.S.) para aí construir o porto da multinacional Marcona Corporation Belga. Era evidente que essa megaoperação econômica representaria tremenda agressão ao meio ambiente e, sobretudo, às populações litorâneas. Em palestra proferida pelo sociólogo dessa multinacional, ouvi, em tom de perfeita satisfação, que não havia encontrado resistência alguma por parte dos numerosos pequenos proprietários e/ou posseiros residentes no enorme território litoral a ser "adquirido" pela multinacional. Ao contrário, todos desejavam vender sua propriedade e transferir-se para a capital, isto é, para a periferia de Vitória. Ao retornar ao mesmo local, 45 anos depois, constato que tudo mudou, infelizmente, para pior.

A questão fundamental que emerge desses e de muitos outros exemplos refere-se à dialética entre valores do território e o poder do dinheiro e da política globalizante: pelas espadas dos romanos, pelos navios venezianos ou pelas caravelas portuguesas, repete-se a mesma triste história. Traduzo com uma metáfora o conceito de dialética entre capital monopolista e território: o interesse financeiro, o capital global, sobrevoa o planeta para escolher o território economicamente mais promissor para nele aterrissar. Esse capital é como um "disco voador global", sem bandeira nacional, sem pátria. Não tem cultura, nem ideal, a não ser a pura ganância, o mero crescimento financeiro. Entretanto, para enriquecer, para crescer sempre mais, feito sanguessuga parasita, precisa de alguma materialidade territorial que apresente condições lucrativas. Ao aterrissar no território escolhido, oferece para todos os moradores sonhos de consumo e de progresso.

Todavia, só pode abrir suas portas "douradas" para uns poucos. Inicialmente, até para muitos. Mas, certamente, não para todos. Assim, divide a comunidade local entre os incluídos no projeto e os excluídos, esfacelando a tradicional solidariedade existente. Breve, o sonho mingua, inclusive para os primeiros incluídos no "dourado" disco voador global, uma vez que muitos deles são dispensados. Expulsos. Desempregados. Destinados a formar a periferia urbana do Rio de Janeiro, Vitória, São Paulo, Recife etc. De repente, o próprio 
"disco voador global" poderá levantar voo à procura de novos territórios mais adequados para seu enriquecimento.

Semelhante aterrisagem, naqueles mesmos anos de 1960 e 1970, ocorria nos campos do norte do Espírito Santo: lá o "dourado" disco voador global levava o nome de Aracruz Celulosa. Quem hoje conta essa história é o Movimento dos Pequenos Agricultores/ES. Até uns anos atrás, essa empresa atuava na produção de eucalipto. De repente, entrou em crise por causa dos vários conflitos com indígenas e quilombolas. Isso desvalorizou seu produto, principalmente na Europa que melhor pagava pela celulose. Mais tarde, a Aracruz Celulosa foi vendida para o grupo Votorantim e passou a se chamar Fibra. Antes, a Aracruz expulsava os pequenos proprietários que iam formar as periferias das grandes cidades (quando não se transformavam em meros funcionários da empresa). Pela resistência do Movimento de Educação do Campo, a renomeada empresa Fibra muda de tática, apresentando-se amigável, com "outra cara", isto é, relaciona-se simpaticamente com a comunidade, financia projetos de piscicultura e outros, o que the gerou internacionalmente melhor mercado. No Estado, a Fibra financia atualmente as campanhas de vários deputados. Eis o depoimento de um integrante do Movimento dos Pequenos Agricultores do E.S.:

A produção de eucalipto, em nosso estado, tem causado muitos danos ao meio ambiente como diminuição das águas. Em Nestor Gomes, São Mateus, onde tem a Escola da Família Agrícola (EFA) do $\mathrm{Km} \mathrm{41,} \mathrm{a} \mathrm{comunidade,} \mathrm{cercada} \mathrm{de} \mathrm{eucalipto,} \mathrm{está}$ quase sem água. A diminuição das águas tem atingido vários municípios da região Norte/ES cobertos de eucalipto, como São Mateus, Conceição da Barra, pois chove pouco e uma árvore de eucalipto retira 20 litros de água/dia do solo. (RACEFFAES, 2012).

Hoje, o antigo disco voador "dourado", Aracruz Celulosa renomeado Fibra, como não pode mais comprar terras neste estado, foi atuar em território da Bahia e do Maranhão e, para garantir matéria prima, trabalha com os agricultores do E.S. em forma de fomento, procurando manter boa relação:

A nossa maior preocupação é que os agricultores se iludem e deixam de produzir alimentos, pois um hectare de terra, ocupado por 6 anos com eucalipto, na forma de fomento, rende $16.000,00$ bruto. Descontando as despesas, sobra muito pouco para os agricultores. (RACEFFAES, 2012). 
Cabe perguntar: tal globalização é uma dialética inevitável? De que forma os territórios precisam se opor aos "discos voadores globais"? Que a dialética de contraposição deve ser utilizada? A mera rejeição de qualquer forma de modernização representaria uma estagnação no passado arcaico, um irracional negar-se à ciência e ao progresso. Então, é possível uma dialética diferente? È a pergunta que Milton Santos nos põe.

\section{Uma pedagogia alternativa}

Se a invasão do capital global é perversa, a estagnação arcaica também precisa ser superada. Por isso, o Movimento de Educação do Campo entendeu ser necessário criar uma nova escola que equilibre a modernidade científica com a solidariedade social, cultural e econômica do território. Isto é, uma escola cuja pedagogia adote como princípio fundamental a fidelidade às culturas do território sem rejeitar a modernização tecnológica. Para isso, portanto, seria necessária uma pedagogia que supere, ao mesmo tempo, a tradicional escola técnica para fixar o homem no campo, mas também a alienante escola de cultura geral urbana que estimula o êxodo dos melhores alunos para os grandes centros.

Com esse objetivo, foi criado no Estado do Espírito Santo, a começar do ano de 1969, o movimento da Pedagogia da Alternância, cuja fórmula pedagógica consiste: cada turma do Ensino Fundamental II frequenta oito dias de aula, em regime de internato, retornando alternativamente durante quinze dias à família ou em outros espaços considerados formativos, visando a desenvolver atividades educativas cujo conteúdo se relacionasse com sua realidade e o estudo das culturas locais, para fortalecer nos alunos o saber e o amor ao seu próprio território. Aqui, preliminarmente, uma equipe passou de comunidade em comunidade (capelas), realizando reuniões de informação e planejamento com lideranças locais, pais, jovens etc. A equipe de operadores, composta por educadores, assistentes sociais, economistas, juristas, médicos, artistas etc., realizava debates sobre o valor do próprio território junto às comunidades de pequenos agricultores familiares, pomeranos, tupiniquins, guaranis, quilombolas. 
Didaticamente, a pedagogia da alternância não é justaposição de espaços e de tempos. Seu currículo, ao contrário, visa a integrar esses polos formativos ao despertar nas consciências dos alunos, das famílias, das instâncias políticas e técnicas um ousado e complexo projeto de desenvolvimento territorial, sustentável, integrador dos valores locais, nacionais e internacionais. Seus principais instrumentos didáticos específicos são: o plano de formação e de estudo; a colocação em comum; o caderno de síntese da realidade; as fichas didáticas; as visitas culturais e as viagens de estudo; os serões, as palestras, os debates; as visitas às famílias dos alunos; os projetos e experiências profissionais; a avaliação contínua. Obviamente, essa proposta pressupõe por parte de Estado a adoção de políticas públicas com vistas à autonomia de gestão das unidades escolares e a garantir recursos regulares por parte dos governos (local, estadual e federal).

Em síntese, o objetivo da pedagogia da alternância, em seus níveis de escolarização fundamental e médio, é recriar nos alunos os valores fundamentais do humanismo, auxiliando-os na identificação de suas individuais inclinações intelectuais, morais e sociais, por meio de uma orgânica e refletida articulação entre escola, família e território. Os educadores dessas escolas sabem que os jovens que os procuram buscam, num nível imediato e superficial da consciência, garantir uma profissão rentável em curto prazo, mas, em profundidade, buscam o conhecimento que thes fora negado devolvendo ao território nativo, numa forma ou noutra, a vitalidade que receberam na infância.

As escolas da Pedagogia da Alternância, atualmente, funcionam em 21 Estados da Federação, totalizando 239 unidades e envolvendo 800 municípios. A perspectiva de expansão gradativa em todo o território nacional é de $10 \%$ ao ano sobre o total de recursos alocados. A Lei de Diretrizes e Bases da Educação Nacional (LDB) no 9.394/96, no artigo 23, cita a alternância como uma das formas de organização escolar. Com base nesse artigo, essa específica pedagogia foi reconhecida por unanimidade pelo Conselho Nacional de Educação em 15 de março de 2006 (Parecer CNE/CEB n 1/2006). 


\section{Conclusão}

O impulso da globalização tende à uniformização cultural, neutralizando e desvalorizando as culturas locais. Na contramão, os movimentos e os debates inspirados na defesa do multiculturalismo reafirmam a necessidade de valorizar as particularidades culturais e identitárias de cada território. Como se sabe, a tradicional posição das esquerdas se caracterizava na defesa intransigente do igualitarismo, uma vez que "a principal luta contra a desigualdade social e econômica absorvia todas as demais lutas" (SAFLATE, 2012, p. 38). Ou seja, o posicionamento político das tradicionais esquerdas era o de indiferença às diferenças. Deveríamos, então, caracterizar como um posicionamento de direita a enfática defesa das diferenças culturais, raciais, territoriais, bandeira do multiculturalismo? Há contradição entre o igualitarismo e o multiculturalismo? A luta pela igualdade socioeconômica fundamenta a valorização das identidades culturais ou estas constituem a fundamentação ético social das luta pela igualdade? Enfim: valorizamos o diferente porque igual a nós ou valorizamos o diferente por ser diferente?

A lógica multiculturalista busca um fundamento seguro para suas teses e lutas, uma vez que as diferenças, em última análise, por si só, traçam algum campo, ainda que variado e amplo, e, com isso, excluem os que habitam fora desse campo. Prova disso é o fato de que a consciência multiculturalista, com frequência, busca justificar-se enfatizando que não pretende excluir ninguém. Ora, por que afirmar o que é obvio? De outro lado, também é verdade que a lógica do igualitarismo, ao afirmar que ama o diferente porque igual e não porque diferente, desatentava para o fato de que é no âmbito e na prática das diferenças culturais que o ser humano expressa sua liberdade.

Com efeito, o igualitarismo tradicional das esquerdas havia-se tornado um princípio absoluto, enrijecido, concebido de forma ideologicamente abstrata, obliterando que o valor máximo do socialismo sempre fora a liberdade, plena e universal. Esquecera, ainda, que, se Marx ardorosamente defendera a igualdade, o fez como garantia ou pressuposto sine qua non da liberdade universal. Leituras equivocadas ou mal intencionadas dos escritos de Marx contrapuseram liberdade a igualdade. Para o socialismo não são dois valores 
contrapostos, nem equivalentes: "A liberdade é valor fim e a igualdade é valor meio" (NOSELLA, 2012b, p. 10).

Com esta premissa, resolve-se a "aparente" contradição entre a lógica igualitarista e a multiculturalista, uma vez que o exercício da liberdade, isto é, da possibilidade de nos expressarmos plena e satisfatoriamente, demanda igualdade de condições econômicas sociais e respeito às práticas das diferenças culturais. Em outras palavras, a luta pela igualdade substantiva e pelos direitos universais do homem inclui o respeito à diversidade cultural. Assim, pode-se concluir que a interculturalidade, ao mesmo tempo em que preserva as manifestações culturais dos diversos povos, promove a integração (não o integrismo), a liberdade, a fraternidade e a igualdade substantiva. Já o multiculturalismo populista exacerbado se origina de uma sub-reptícia postura de confrontação e até de conformação às desigualdades; é reflexo do abandono da luta pela hegemonia político cultural dos valores humanistas plenos; é a ideologia pós-moderna em seu aspecto de laissez faire política e eticamente descompromissado.

\section{Referências}

FOERSTE, Erineu; PAIXÃO, Laura. M. B; CALIARI, Rogério (Org.) Educação do campo: diálogos interculturais em 'terras capixabas'. Vitória: EDUFES, 2012. (no prelo)

GAMBINO, Antonio. Le minoranze culturali. in SANTARONE, Donatello (coord.). Multiculturalismo. Milano: G.B. Palumbo Editore. p.17-20, 2001.

GARZANTI. I grandi dizionari italiano. Milano: Garzanti Linguistica, 2011.

HUAISS, Antônio; VILLAR, Mauro de Salles; FRANCO, Francisco Manoel de Mello. Dicionário Huaiss da Língua Portuguesa. Rio de Janeiro: Objetiva, 2001.

NOSELLA, Paolo (2012a). Origens da Pedagogia da Alternância no Brasil. Vitória: Editora EDUFES, 2012a,

NOSELLA, Paolo (2012b). Prefácio. In: MANACORDA, Mario Alighiero. Karl Marx e a liberdade. Campinas/SP, Ed. Alínea. p. 9-10, 2012b.

RACEFFAES (2012). Informação urgente. [mensagem pessoal]. Mensagens recebidas por nosellap@terra.com.br em 08 dezembro de 2012. 
RAVEAUD, Maroussia. Multiculturalismo. In: ZANTEN, Agnés van (Coord.). Dicionário de Educação. Petrópolis: Vozes. p. 592-597, 2011.

SAFATLE, Vladimir. Ensaio de Orquestra. In: Cult - Revista Brasileira de Cultura. São Paulo, no.169. p. 35-38, 2012.

SANTOS, Milton. Por uma outra globalização. Rio de Janeiro: Record.

TARIM, Stefania. Etica e política nell'epoca dell'interculturalitá. In: Crítica marxista, Roma, $n^{\circ}$ 5. p. 63-66, 2010.

\section{Sobre os Autores}

\section{Paolo Nosella}

nosellap@terra.com.br

Paolo Nosella licenciou-se em Filosofia na Itália, onde nasceu em 1942. Em 1967, veio ao Brasil para trabalhar em educação popular na criação das primeiras escolas da Pedagogia da Alternância. Fez mestrado e doutorado em Filosofia da Educação na PUC/SP.

É professor titular em Filosofia da Educação na Universidade Federal de São Carlos/SP (UFSCar). Aposentado, atua na mesma como colaborador do PPGE. É pesquisador Sênior do CNPq.

Autor dos livros: Origens da Pedagogia da Alternância no Brasil ( EDUFES, 2013), Instituições escolares - por que e como pesquisar (Alínea Editora, 21 o13), Ensino Médio à luz do pensamento de Gramsci ( Alínea Editora, 2016), A escola de Gramsci ( $5^{a}$ edição ampliada, Cortez Editora, 